\title{
REBECA MALTRATADA: UN ESTUDIO COMPARATIVO DE SU CENSURA A TRAVÉS DE LAS LEYES DE PRENSA ESPAÑOLAS Y EL CÓDICO HAYS ESTADOUNIDENSE
}

\author{
Gora Zaragoza Ninet* y Beatriz Cerezo Merchán** \\ Universitat de València
}

\section{RESUMEN}

En 1938, la escritora inglesa Daphne du Maurier (1907-1989) completaba la escritura de Rebecca. En 1940, se estrenaba la adaptación cinematográfica, dirigida por Alfred Hitchcock. La escasa estima que sentía Hitchcock por la novela original, así como los fundamentos del puritano Código Hays (1930), hicieron que el guion original tuviera que ser enmendado. Paralelamente, en 1938, se imponía en España la Ley de Prensa, que pondría al servicio del régimen franquista toda la producción literaria. Sin embargo, la censura franquista dio carta blanca a Rebeca (novela y adaptación cinematográfica). En este trabajo analizamos los comportamientos censores de ambos códigos, coetáneos y similares en cuanto a ideario, para concluir que fue precisamente lo que el Código Hays trató de ocultar lo que motivaría a la censura franquista a aplaudir el relato.

Palabras Clave: Rebeca, censura, Código Hays, Leyes de Prensa españolas, adaptación cinematográfica.

\section{REBECCA ABUSED: A COMPARATIVE ANALYSIS OF CENSORSHIP IN THE NOVEL AND ITS FILM ADAPTATION}

\section{Abstract}

In 1938, the English writer Daphne du Maurier (1907-1989) finished writing Rebecca. In 1940, the film adaptation, directed by Alfred Hitchcock, was released. On the one hand, Hitchcock's scant regard for the novel, and, on the other, the foundations of the puritan Hays Code (1930), resulted in the original script being amended. Concurrently, in 1938, the Spanish Press Law placed all literary production at the service of the Franco regime. However, the Francoist censorship gave carte blanche to Rebeca (both to novel and film adaptation). In this paper we study the censoring behaviours of both codes, which had similar foundations and ideology, to conclude that it was precisely what the Hays Code tried to conceal what motivated the appraisal of the book in Spain.

Keywords: Rebecca, Censorship, Hays Production Code, Spanish Press Laws, film adaptation. 


\section{INTRODUCCIÓN}

En 1938 y no sin pocos esfuerzos, como cuenta Margaret Forster (133), autora de una de las biografías más importantes escritas sobre la novelista inglesa, Daphne du Maurier (Londres, 1907-Cornualles, 1989) terminaba la redacción de Rebecca en un momento de escasa fuerza física y mental que le había ido impidiendo avanzar en la escritura pese a la presión de su editor, Victor Gollancz. En esta biografía se destaca a Du Maurier como una mujer independiente y ajena a los roles típicamente asociados a la mujer: «[she] was never slow to ask her parents for favours, in spite of her desire to be independent [...] she was finding housekeeping "a bit of a cope" [...]. Any kind of cooking was beyond her» (FORSTER 101). La autora de Rebecca reconocía las complicaciones de la vida marital y huyó de ser una esposa-madre. Estos datos biográficos nos parecen esenciales para poder entender, por un lado, la obra Rebecca y, por otro, el que será el objetivo principal de nuestro trabajo: analizar la recepción de la obra en España, incidiendo en los comportamientos censores que regían en la época (las Leyes de Prensa en España y el Código Hays en Estados Unidos) y los posos ideológicos diferenciados entre censura estadounidense y censura española. Asimismo, observaremos cómo estos influenciaron el choque entre los personajes literarios y cinematográficos.

En el momento de la publicación de la obra original en 1938 y de su primera traducción al español, una versión de Fernando Calleja publicada en 1943, en España imperaba la Ley de Prensa de 1938, promulgada el 22 de abril de 1938. Obra de Ramón Serrano Suñer, ministro de la Gobernación entre 1938 y 1940, fue una de las consecuencias de la Guerra Civil española (1936-1939) y de la instauración de la dictadura franquista. La Ley de Prensa de 1938 tenía como objetivo frenar la prensa republicana y poner el conjunto de la prensa al servicio del Estado fascista. Así, todo material escrito o audiovisual, idea o expresión autóctona o foránea quedaba al servicio del régimen franquista y sujeto a un estricto aparato de censura que resumía la ideología y moral del franquismo. La novela posee varios aspectos y matices que bien podrían haber impedido su publicación en España. En primer lugar, el propio personaje de Rebeca, una mujer fuerte, independiente, adúltera y nulípara en las antípodas del 'ángel del hogar' del ideario franquista: una mujer supeditada a su marido y cuya función en la vida se reduce a la procreación. En segundo lugar, los matices lésbicos del ama de llaves. Y, en tercer lugar, la sensualidad inherente al conjunto de la novela. Sin embargo, el régimen franquista aceptó todos y cada uno de los intentos de publicación y reimpresión de la novela en España. No obstante, como también veremos en el presente artículo, la adaptación teatral de la misma, llevada al escenario por Rambal, Soriano Torres y Pérez Bultó en 1943, no tuvo la misma fortuna y sufrió los rigores de la Ley de Prensa.

*E-mail: gora.zaragoza@uv.es.

**E-mail: beatriz.cerezo@uv.es. 
El 12 de abril de 1940 se estrenaba la adaptación cinematográfica de la novela en Estados Unidos, dirigida por el afamado director inglés Alfred Hitchcock y producida por Selznick International Pictures. Fue el primer proyecto estadounidense de Hitchcock y obtuvo dos Oscars (incluido el de Mejor película) de un total de once nominaciones. Sin embargo, la adaptación al cine en tierras estadounidenses no corrió la misma suerte que la traducción de la novela en España. El guion de la película tuvo que ser corregido y adaptado para adecuarse a la moral del Código Hays, en contra de la voluntad del productor, Selznick, quien rehusaba alterar la historia de la novela original para no ofender ni a la autora ni a sus lectores.

¿Cómo una misma obra fue aceptada e incluso loada por los lectores encargados de la censura franquista en su versión literaria y, sin embargo, tuvo que ser adaptada para que fuera aprobada por la moral católica y conservadora estadounidense? Despejar esta incógnita será el principal objetivo de nuestro estudio.

\section{REBECCA: OBRA LITERARIA ORIGINAL Y ADAPTACIONES}

Rebecca (1938) es una historia gótica sobre el recuerdo del personaje que da nombre al relato, así como sobre Maxim de Winter, el personaje masculino principal; su nueva esposa, la inocente segunda Sra. De Winter; y la Sra. Danvers, el ama de llaves de Manderley. Resulta evidente el matiz autobiográfico que la autora volcó en la segunda Sra. de Winter (sin nombre en la obra), ya que ella también se sentía marginada y excluida del mundo con frecuencia, como analiza Forster: «She herself felt an outcast, an outsider, someone who did not fit in and was aware of it» (134). La obra, a menudo degradada como literatura popular, ficción «gótica» o romance, fue un éxito, y los editores de Du Maurier quedaron desde el principio maravillados con su inusual calidad literaria y genio para la creación de intrigas, como queda reflejado en su biografía: «It was [...] sentimental, but in a haunting, melancholy way, which captured the reader's attention and sympathy from the very first paragraph. But it was also passionate [...] not that there is any sign of physical passion and, though melodramatic, brilliantly creates a sense of atmosphere and suspense» (Forster 136). Pese a su sensualidad -en el sentido más general de exploración y exaltación de todos los sentidos-, la novela obviaba cualquier hecho físico, lo que probablemente fuera uno de los factores que influyeron en que la novela superara la censura franquista desde el principio y en cada una de sus posteriores ediciones. Sobra decir que los censores franquistas no habrían aceptado ninguna alusión sexual explícita. Además, en todos los expedientes de censura de la novela se alude a la adaptación cinematográfica. Aquella calidad literaria que alaban los editores ingleses de Du Maurier queda supeditada al éxito y talento de la adaptación cinematográfica de Hitchcock. Bravo (27) explica que ninguna de las obras maestras de Alfred Hitchcock está basada en obras maestras de la literatura, y cita a varios escritores «menores» donde ni siquiera figura Du Maurier. Como recalca Bell: «Though Du Maurier's books have always been popular, they have not always been considered highly literary works». Parece que Hitchcock tan solo buscaba historias en las que inspirarse: «What I do is to read a story only once, and if I like the basic idea, I just forget all about the book and start to create cinema. Today I 
would be unable to tell you the story of Daphne du Maurier's The Birds. I read it only once, and very quickly at that» (COE). Pero no parece que Hitchcock se olvidara de Rebecca tan rápido, y las modificaciones fueron parte obra suya -pues menospreciaba la obra- parte fruto del Código de Producción de Hollywood, que censuraba determinados comportamientos en pantalla.

Barr (116) puntualiza que Hitchcock dirigió tres adaptaciones de relatos de la autora: Jamaica Inn (1939), Rebecca (1940) y The Birds (1963). La última de las tres adaptaciones tampoco estuvo exenta de polémica, pues ya existía una obra muy similar de otro escritor, Frank Baker: «Thirty years before Du Maurier's short story, Frank Baker wrote The Birds, in which Londoners were attacked by avian predators» (Fow LER). De hecho, fue a raíz de la adaptación cinematográfica cuando empezaron a lloverle a la autora denuncias de plagio. Du Maurier no había quedado satisfecha con la adaptación cinematográfica que Hitchcock había realizado de su anterior novela (ni la crítica ni el público), Jamaica Inn (1939), y presionó mucho para que Rebecca se ajustara a la novela. Tampoco Du Maurier quedaría satisfecha años más tarde con la adaptación de The Birds: «Daphne hated the film and couldn't understand why Hitchcock had so distorted her story» (Forster 437). En cuanto a la adaptación de Rebecca, Selznick compartía el deseo de la escritora y no quería alterar demasiado la novela original. Además, opinaba que el Código Hays era una importante traba para el arte. Pero Hitchcock menospreciaba la novela e introdujo en el guion varios cambios que no gustarían al productor:

Hitchcock, por su parte, despreció la novela desde el primer momento calificándola de «novelette», de literatura femenina, y desde los primeros planteamientos del guion decidió suprimir buena parte de la novela y modificar muchos de los personajes con la ayuda de su esposa Alma y diversos guionistas intentando aprovechar el esqueleto de la novela para hacer un guion con su sello. A tal efecto, introdujo diversas escenas de humor totalmente ausentes en el texto original y diversos elementos para borrar el espíritu femenino de la novela. Así pues, modificó la esencia de todos los personajes y cuando Selznick leyó el borrador del guion del 3 de junio se quedó horrorizado de lo que, a su juicio, Hitchcock había hecho con la novela original (Del Toro 98).

Por otra parte, Hitchcock tuvo que plegarse a las exigencias del Código Hays. Así, lo que no supuso ningún problema para la moral católica del régimen de Franco -que Maxim de Winter fuera sospechoso de haber asesinado a su primera esposa durante gran parte de la película- tuvo que ser sustituido en la adaptación cinematográfica por la muerte accidental de esta.

Hitchcock siempre apuntaba a la vez a una audiencia popular e intelectual. Cuando adaptaba novelas largas como Rebecca, no eran experiencias satisfactorias (BArr 120). En Rebecca, Hitchcock sustituyó los paisajes de Cornualles, donde se sitúa la historia original, por los acantilados de Point Lobos, California, que evocaban la misma atmósfera opresiva de la novela original. En los créditos de 1940 se puede leer: «Selznick International presents its picturization of Daphne du Maurier's Rebecca». En la siguiente versión hay un ligero cambio: «The Selznick Studio presents its production of Daphne du Maurier's Rebecca». Aparte de la ausencia de alusiones sexuales explícitas que hemos comentado anteriormente, creemos que otra 
de las razones por las que la novela superó la censura franquista es porque la relación asimétrica entre el Sr. De Winter y su esposa, la segunda Sra. De Winter, se adaptaba perfectamente a la moral católica del régimen franquista. Estamos frente a un marido que humilla a su mujer, quien responde con servidumbre, reclamando amor, cualquier tipo de amor. Tras conocer el asesinato de Rebeca a manos de su marido, le ofrece el amor de la amistad, definidos por Du Maurier en términos masculinos, como último y desesperado recurso: "I'll be your friend and companion, a sort of boy. I don't ever want more than that» (Du Maurier 203). En la adaptación teatral de la novela en español (Rambal, Soriano Torres y Pérez Bultó 1944), sin embargo, este ofrecimiento de amor se expresa en términos femeninos: «No te pido que me quieras, como a ella, ipues ya sé que eso es imposible! Pero seré tu amiga, tu compañera... Nunca aspiré a otra cosa. ¿Crees que es pedirte demasiado?» (24). Sin embargo, en la versión española de la novela traducida por Gloria Martínez en 1993, la traducción es muy ambigua: «No te voy a decir que me quieras, porque no quiero pedirte imposibles; sólo quiero ser tu amiga, tu compańera, como si fuera un chico" (Du Maurier 292, trad. de Gloria Martínez). Esta versión no consigue evocar el matiz de la frase original donde la segunda Sra. De Winter ofrece la amistad masculina, lo máximo a lo que puede aspirar.

\section{REBECA CENSURADA}

\subsection{Censura: Definición}

La censura es una restricción a la expresión pública de ideas y opiniones, un acto de fuerza que las manipula y controla. Como Billiani (8) apunta:

La censura es un acto coercitivo y enérgico que bloquea, manipula y controla la interacción intercultural de varias maneras. Debe entenderse como uno de los discursos, con frecuencia el dominante, articulado por una sociedad determinada en un momento dado y expresado a través de prácticas culturales, estéticas, lingüísticas y económicas represivas (nuestra traducción).

Encontramos esta definición especialmente interesante por dos motivos. En primer lugar, porque destaca que la censura controla la interacción entre culturas, y, en segundo, porque esta se puede aplicar en distintos contextos y en expresiones de distinta naturaleza. En nuestra investigación estudiamos dos contextos, dos culturas, vemos cómo la traducción y la adaptación pueden llegar a manipular el texto original, y nos centramos en analizar y comparar las restricciones interpuestas por la censura española y estadounidense a la novela y a la versión cinematográfica de la obra Rebecca.

\subsection{LA CENSURA DURANTE LA DICTADURA FRANQUISTA}

En nuestro país, como hemos visto, la censura se vincula, inevitablemente, a la dictadura franquista, y fueron las Leyes de Prensa de 1938 y 1966 las que legitimaron esta censura. Sin embargo, «nunca hubo criterios objetivos ni normas con- 
cretas de aplicación; tal vez ni siquiera podía haberlas. En la práctica, la censura se orientaba de acuerdo con unos cánones que permanecieron invariables durante las casi cuatro décadas de dictadura de Franco» (Neuschäfer 49). Efectivamente, los criterios aplicados en la práctica censora siempre fueron de la mano de factores coyunturales de tipo religioso, social y político que tuvieron lugar en el transcurso de esas cuatro décadas, tanto dentro de nuestras fronteras como en el ámbito internacional. Por tanto, la censura nunca gozó de autonomía total, lo que se tradujo en la arbitrariedad de la labor de los censores y de la administración (CisQuella, Erviti y Sorolla 100-04). A pesar de esta inestabilidad, sí que existieron unos cánones más o menos estables durante el franquismo, que Martos (258-259) resume del siguiente modo:

1. Opiniones políticas: el régimen y Franco son intocables.

2. Moral sexual: prohibición de hacer referencia a todo lo concerniente al sexto mandamiento, y a lo que implicara un atentado contra el pudor y las buenas costumbres (relaciones sexuales sin matrimonio, adulterio...). Abstención también de hacer referencias a la homosexualidad, el divorcio o el aborto.

3. Uso del lenguaje: prohibición de emplear un lenguaje indecoroso, provocativo e impropio de los buenos modales.

4. Dogma: inhibición de todo lo contrario al dogma católico o las instituciones religiosas.

El sistema de censura en España estaba organizado en tres niveles: lectores, dictaminadores y responsables efectivos de la censura (ABELLÁn 115). Los lectores se encargaban de resumir el contenido de la obra, rellenar el formulario de censura e indicar si había páginas conflictivas susceptibles de ser censuradas total o parcialmente. Si este era el caso, se procedía a la eliminación del contenido juzgado como «No Publicable» y el editor debía presentar pruebas de los cambios realizados para que se reconsiderara la publicación de la obra.

El sistema censorio español se dividía en tres secciones: obras literarias, teatro y cine, y prensa, y fue el responsable de una cifra incalculable de prohibiciones parciales o totales de obras (ZARAGOZA et al. 210-211). Es, por tanto, necesario investigar cómo la censura condicionó la producción, traducción y adaptación de obras de distinta naturaleza (literarias, teatrales, cinematográficas o periodísticas) desde el punto de vista temático y estilístico.

En nuestro país, probablemente fueran el teatro y el cine las áreas que sufrieran un control más estricto, ya que se entendía que estas podían ejercer mayor influencia sobre la opinión pública (Neuschäfer 51). En las películas, por ejemplo, se llegaban a exigir cambios o cortes más o menos extensos, de los cuales el público se solía dar cuenta, ya que en muchas ocasiones estos provocaban situaciones inverosímiles. Esto se hacía aún más evidente en las películas dobladas que llegaban a nuestro país (no faltan casos de maridos o amantes de las protagonistas que se convertían en hermanos, como es el caso de Mogambo, 1953, película en cuya versión al español el adulterio se convierte en incesto). En cuanto al teatro, su percepción y peligro como elemento adoctrinador y arma propagandística 
por parte del régimen resultaba evidente, habida cuenta de que este se lanzaba a un público en masa y su efecto era rápido e instantáneo, mientras que los efectos de un libro, por ejemplo, eran más lentos y se producían en el retiro de lectura de cada lector (MuÑoz 20).

La censura en esta época en España inhibía la comunicación y llevaba a los autores a ejercer una suerte de autocensura, a la vez que estimulaba su imaginación, ya que estos siempre buscaban la forma de burlarla. Algunos mecanismos podían ser hablar en clave en lugar de utilizar expresiones directas, moderar el discurso para hacerlo parecer más comedido o camuflar la comunicación mediante otros mecanismos (como pudieran ser la imagen o la música en el cine y el teatro, por ejemplo) para que el censor, desorientado, fuera incapaz de percibir su sentido (NeUSCHÄFER 56).

\subsubsection{Rebecca frente a las Leyes de Prensa españolas de 1938 y 1966}

Según datos de la Biblioteca Nacional de España, a día de hoy existen 38 reediciones de la traducción de Rebecca al español. La primera versión de la novela al español data de 1942, y en lugar de ser una traducción completa de la novela es una traducción abreviada basada en la versión cinematográfica. Esta traducción y adaptación, firmada por Fernando Calleja y editada por la editorial La Nave, fue reeditada por la misma editorial al año siguiente, en 1943, con una versión completa de la novela de Daphne du Maurier. Todas las traducciones al español posteriores a esta fecha, a excepción de una traducción de 1993 firmada por Gloria Martínez y editada por Ediciones B, son reediciones de la traducción de Calleja.

Tal y como señalamos en un estudio anterior (ZARAGOZA et al. 212), en el Archivo General de la Administración (en adelante, AGA) constan 26 expedientes de censura de la traducción de la novela, redactados entre 1942 y 1982. Rebeca pasó todos los filtros de la censura franquista, en cada uno de los intentos de publicación de la novela traducida y en cada una de sus ediciones o portadas. Tras estudiar todos los expedientes de censura de la traducción de la novela (a excepción de un primer expediente de 1942 extraviado) existentes en el AGA, podemos concluir que el éxito de la adaptación cinematográfica de Hitchcock llegó a eclipsar a la escritora y fue uno de los principales motivos que llevaron a los censores franquistas a dar carta blanca reiteradamente a la novela. A continuación reproducimos algunos de los comentarios de los censores del régimen a este respecto:

- «Matiz político: apolítico». $(1943)^{1}$

- «Novela fuerte y algo morbosa aunque no inmoral». $(1953)^{2}$

\footnotetext{
${ }^{1}$ Archivo General de la Administración, Sección de Cultura, expediente 1946, caja 21/07129.

2 Archivo General de la Administración, Sección de Cultura, expediente 420, caja 21/10172.
} 
- «Nada que oponer a esta nueva edición de la famosa novela que popularizó el cine hace algunos años. Puede autorizarse». $(1958)^{3}$

En cuanto a la adaptación cinematográfica (cuya traductora para el doblaje fue Irene Guerrero de Luna), no hay expedientes de censura de la traducción y doblaje de la adaptación cinematográfica. En nuestro estudio, llevado a cabo en el AGA, únicamente encontramos un expediente de censura, correspondiente al tráiler de la película, distribuido por Mercurio Films, que fue aprobado completamente (y tolerado para menores de 16 ańos) el 1 de diciembre de $1942^{4}$. No encontramos, sin embargo, ningún expediente de censura de la película doblada al español, pero el estudio exhaustivo de la versión en inglés en comparación con la versión en castellano nos permite comprobar que la versión en nuestro idioma es un reflejo fiel y completo del original y que no muestra rasgos de censura ni en lo que se refiere a escenas ni en lo concerniente a diálogos.

El gran éxito de la versión cinematográfica de Hitchcock en nuestro país influyó también en la adaptación de la novela a otros formatos. En España, Rebecca fue traducida y adaptada al teatro por Enrique Rambal, Manuel Soriano Torres y José Javier Pérez Bultó. Según datos del AGA, la primera solicitud de autorización de la obra teatral se realiza el 14 de abril de 1943, acompañada de un libreto titulado Rebeca. Escenificación en tres actos y un prólogo, de la novela de Daphne du Maurier. El día 28 de ese mismo mes, con número de expediente R-4019, la Vicesecretaría de Educación Popular resuelve autorizarla. Sin embargo, sobre esa autorización figura, escrita a mano, la petición de una revisión de la autorización que reza del siguiente modo: «Pedir la revisión y prohibirla por amoral. Es un paso más hacia el Rebequismo». Respondiendo a tal solicitud, la adaptación teatral de Rebeca vuelve a ser revisada y el 26 de agosto de 1943 se decreta su prohibición. Acompañando a esta prohibición, y sin indicaciones de qué páginas o pasajes suprimir o modificar, se encuentra el siguiente texto del censor: «La curiosidad morbosa que despertó en el público español la proyección de la película "Rebeca" -que se tradujo además en repetidas ediciones de la novela del mismo título- no merece ser aireada nuevamente con la representación escénica de dicha obra. Por consiguiente, estimo que no debe autorizarse».

Sin embargo, la información que encontramos en los archivos de la Administración revela que esta prohibición del aparato censor franquista debió de traspapelarse y no llegó a manos de la Vicesecretaría de Educación Popular hasta principios de 1944 , lo que supuso que la obra fuera representada en más de cien ocasiones en teatros nacionales durante todo 1943. No fue hasta el 11 de febrero de 1944 cuando la Vicesecretaría de Educación Popular recibió un telegrama en el que se comuni-

\footnotetext{
3 Archivo General de la Administración, Sección de Cultura, expediente 4038, caja $21 / 12113$

${ }^{4}$ Archivo General de la Administración, Sección de Cultura, expediente 03793, caja $36 / 03188$.
} 
caba la prohibición de la obra con fecha de 26 de agosto de 1943. Tras este aviso, se anularon todas las representaciones teatrales programadas y se incautó la propaganda relativa a la representación teatral. Dos meses más tarde, el 4 de abril de 1944, se entrega a la Sección de cine y teatro una nueva solicitud de aprobación de la adaptación teatral, esta vez acompańada de un nuevo libreto, corregido y resumido, con título Comedia dramática de gran espectáculo, en un prólogo y dos jornadas, divididas en veintisiete cuadros, adaptación de la novela del mismo título de Daphne du Maurier (Rambal, Soriano Torres y Pérez Bultó 1944). El 28 de ese mismo mes, desde la Vicesecretaría de Educación Popular, el censor Guillermo de Reyna emite la siguiente valoración: «Breve exposición del argumento: Sobradamente conocido es de los organismos de la Delegación de Propaganda, el argumento de "Rebeca", por lo cual hago gracia de sintetizarlo. La adaptación de Rambal, tiene el mérito de sujetarse a la novela original, presentando así a Rebeca como justamente asesinada por su marido, apartándose de la versión de la película americana, que por sujetarse a las normas de censura de los EE. UU. la hacía morir por causa de un accidente provocado sin intención por el marido. Entiende el que suscribe, que la versión original está más de acuerdo con nuestro concepto calderoniano de la existencia, por lo cual aplaude sin reservas, que Rambal haya devuelto en su adaptación, el normal coraje y la violenta reacción del marido ante la esposa adúltera:

[...] Matiz político: no tiene

Matiz religioso: carece

Juicio general que merece al censor: aceptable

Tachaduras páginas: -

Correcciones páginas: -

[...]

Alguna otra observación que el censor considere pertinente: Puede autorizarse».

La adaptación teatral española, resumida y modificada en numerosos actos con respecto al libreto presentado inicialmente, fue, por tanto, aprobada definitivamente para su representación. Dado que en el presente estudio analizamos los diferentes procesos de mutilación que ha sufrido Rebecca (película, novela, obra de teatro), el análisis y la comparación de las dos versiones de la adaptación teatral al español con respecto a la novela original o la película constituiría el objeto de estudio de otro trabajo, por lo que no le dedicaremos más líneas aquí.

\subsection{El Código de PROdUCCión de Hollywood}

Antes de la instauración del código, y tras el final de la Primera Guerra Mundial, cambia la representación de la mujer en el cine. Como señala Montiel, «la figura de la mujer maternal y abnegada fue sustituida por la vampiresa representada por Theda Bara o Clara Bow o por mujeres independientes en todos los sentidos como Gloria Swanson o Joan Crawford» (61). Como en la II República española, las mujeres gozaban de libertades y derechos fundamentales que se vieron aniquilados tras la Guerra Civil y con el advenimiento de la dictadura franquista. Del mismo 
modo, con la instauración del Código Hays, se pretendía una reforma ideológica donde "la naturaleza de las mujeres es ser pasivas u objetos de deseo» (RodríGUez 191). En la adaptación cinematográfica de Rebecca, puede verse claramente lo que Bou describe como la «sublimación de Eros desde la espiritualidad» (19), una de las consecuencias del no siempre fácil cumplimiento del Código Hays que se materializó en una «sexualidad idealizada que transfiguraba el cuerpo y transmitía que la unión carnal era una vivencia extraordinaria y trascendente» (Bou 29).

Como señala Rodríguez, el código de producción de Hollywood, de 1930, no fue una imposición de la Iglesia católica, sino de fuerzas más poderosas y numerosas: la banca. Hollywood era el mayor centro de difusión cultural a nivel mundial y esto contribuyó significativamente a la edificación de una hegemonía cultural e ideológica (180), así como a la construcción de lo que hoy día se conoce como el cine clásico. Tal y como apuntan Hernández y Martín:

Del mismo modo que la existencia de motivaciones de índole económica en su adopción no impide que la puesta en marcha de dicho reglamento pueda inscribirse, además, como una de las últimas batallas en la disputa social, librada durante las primeras décadas del siglo xx, por el lugar que debía ocupar el cine como arte y medio de entretenimiento y que condujeron a la configuración de los rasgos esenciales que definen lo que hoy conocemos como cine clásico (7).

En 1927, William Hays, presidente de la asociación de productoras de Hollywood (la MPPDA), trató de imponer unas recomendaciones que deberían seguir las películas (conocidas como las Don't and Be careful), pero los productores no las acataron, ya que el sexo y la violencia en pantalla eran éxitos de taquilla. La Iglesia católica amenazó con prohibir a sus feligreses ir al cine, por lo que los productores cedieron a la presión. En 1930, Hays consiguió que la MPPDA adoptara un nuevo código (redactado por el sacerdote jesuita Daniel Lord y el periodista Martin Quigley) y dejó en el Studio Relations Committee su cumplimiento. Sin embargo, estos resultaron ser demasiado laxos, por lo que Hays creó una oficina específica para la aplicación del código: la Production Code Administration. En 1934 los productores ya se habían sometido, y a partir de ese momento debían enviar (igual que pasaba con la censura franquista, donde el editor siempre tenía que enviar al comité de censura el libro para el cual solicitaba permiso de publicación) los guiones a la PCA, de manera que determinadas escenas pasaran por su filtro. Como explica Rodríguez, los verdaderos dueños de Hollywood eran los banqueros de Nueva York, que ponían el dinero para las producciones y, por tanto, a quienes los productores debían rendir cuentas luego (184). El presidente del Banco de América advirtió que ningún proyecto tendría financiación sin la autorización de la PCA, por lo que, según explica Doherty, «la Iglesia católica se encontró de repente con el apoyo del establishment económico estadounidense, deseoso de frenar las tendencias filocomunistas y temeroso de que su bondad, poder y liderazgo fueran cuestionados» (Rodríguez 185). Y así, el católico radical y antisemita Joseph Breen ocuparía el puesto más importante. El núcleo del Código Hays era moral: las películas debían evitar la sordidez, temas escabrosos como las relaciones extramatrimoniales, el aborto o las relaciones interraciales (Rodríguez 186), así como 
las bajas pasiones, las escenas de parto o abuso de alcohol; debían respetar la santidad del matrimonio y no ridiculizar a la Iglesia, tal y como recogía la Ley de Prensa española de 1938. Prohibía la vulgaridad, la obscenidad, la blasfemia, la irreverencia, la desnudez y cualquier insinuación. Además de tabú, la homosexualidad quedaba excluida de las pantallas. Siguiendo este marco de conducta maniqueísta, el bien debía triunfar siempre sobre el mal, y toda película debía incluir una lección moral. Los buenos debían ser siempre interpretados por estrellas, y no por actores secundarios. Además, el código incluía normas sobre la representación en las películas, si bien en 1966 el código fue abandonado y sustituido por el sistema actual de catalogación por edades, pero en los treinta años en que estuvo vigente «su influencia fue devastadora" (RoDríguez 192).

\subsubsection{Rebeca frente al Código Hays}

Como apuntábamos con anterioridad, el tratamiento que Hitchcock dio a la novela de Du Maurier fue más allá de lo que la autora y de lo que Selznick, el productor, encontraban permisible. Mientras muchos de los cambios que Hitchcock había realizado en la adaptación de la novela al guion cinematográfico tenían que ver con la conversión de esta a un formato más cinematográfico, otros eran, simplemente, una herramienta para transformar la novela de Du Maurier en algo que el público identificara rápidamente como un thriller hitchcockniano (Boyd 119).

Cuando Selznick vio la primera versión del guion terminada, ordenó que se le diera un nuevo tratamiento al guion para que prevalecieran muchos elementos y esencias de los personajes de la novela de los que Hitchcock se había deshecho, y supervisó personalmente el rodaje de numerosas escenas. Tras muchos borradores, el guion definitivo de la película vio la luz el 7 de septiembre de 1939 (Del Toro 98). Sin embargo, en estas negociaciones sobre el guion definitivo el Código de Producción de Hollywood también tuvo mucho que decir, y fue el responsable de algunas de las diferencias fundamentales entre la novela y la película.

Joseph Breen, presidente de la PCA, fue muy claro en cuanto a lo que el Código Hays no admitiría en la película. En una carta a Selznick, Breen realizó un listado de todas las transgresiones que presentaba el guion original:

Hemos leído el guion provisional [...] y lamento informarle de que el material, a nuestro juicio, está definitiva y específicamente en violación del Código de Producción [...]. La objeción específica a este material es triple: (a) Como está escrito ahora, es la historia de un asesino, a quien se le permite salir impune; (b) Las interferencias bastante evidentes de perversión sexual; y (c) Las continuas referencias en el diálogo a la supuesta relación ilícita entre Favell y la primera Sra. De Winter, y las referencias frecuentes al presunto hijo ilegítimo (BERENSTEIN 17) (nuestra traducción).

Resulta evidente que por 'perversión sexual' Breen hacía referencia al lesbianismo subyacente en la relación Danvers-Rebeca, como especificaba en otra carta que envió a Selznick: 
Será absolutamente necesario que no haya sugerencia de ningún tipo de una relación pervertida entre la Sra. Danvers y Rebecca. Si algún indicio de esto se desliza en esta escena, es evidente que no podremos aprobarla. Específicamente, tenemos en mente la descripción de la señora Danvers de los atributos físicos de Rebecca y cuando coge las diversas prendas, particularmente el camisón (BERENSTEIN 18) (nuestra traducción).

Finalmente, parece que Breen cedió a dos de estas transgresiones. Por una parte, aceptó la relación de adulterio de Rebeca con su primo Favell por exigencias de la historia. Por otra, excepto para los espectadores más inocentes, las evidentes interferencias de perversión sexual (por ejemplo, la escena en que la Sra. Danvers se frota unas pieles de Rebecca por el rostro afirmando: «Es suave, ¿ंverdad? Puedes sentirlo, ¿verdad?») siguieron resultando evidentes en la película. De hecho, como veremos a continuación cuando analicemos la escena, estas referencias resultan más obvias en pantalla que en la novela, pese a que los diálogos del guion no sean más explícitos que los del libro. Entendemos, por tanto, que la PCA dio su aprobación a la película, aunque estas referencias persistieran.

La posibilidad de que el asesino quedase impune era, sin embargo, algo que Breen no estaba dispuesto a tolerar, por lo que sugirió a Selznick que este asesinato presente en la novela se convirtiera en una muerte accidental en la película. A pesar de la disconformidad de Selznick («Toda la historia de Rebecca es la historia de un hombre que asesinó a su esposa [...] y ahora se convierte en la historia de un hombre que ha enterrado a una mujer que fue asesinada accidentalmente [nuestra traducción]» [Boyd 121], este fue el final que tuvieron que aceptar, como veremos a continuación.

\subsection{ANÁlisis COMPARATIVO DE LA VERSIÓN LITERARIA Y CINEMATOGRÁFICA DE REBECCA}

Para ilustrar las divergencias entre la novela y la adaptación cinematográfica como resultado de la aplicación de los códigos censores, analizamos cuatro escenas: la de la confesión de asesinato, la del final del caso, la de Manderley en llamas y, por último, la que tiene lugar cuando la Sra. Danvers muestra a la segunda Sra. De Winter la habitación de Rebeca. En este análisis compararemos dos versiones: 1) la versión traducida de la novela al español y 2) la versión cinematográfica de Hitchcock doblada al español, ambas traducciones fieles y completas de las obras originales en inglés. El énfasis en frases clave de estas escenas, en cursiva, es nuestro.

\section{ESCENA 1: LA CONFESIÓN}

\section{TeXto Literario}

Capitulo XIX

Maxim de Winter: -Sí. La mujer enterrada en el panteón no es Rebeca. Es el cuerpo de una mujer desconocida que nadie reclamó, que nadie sabe de 


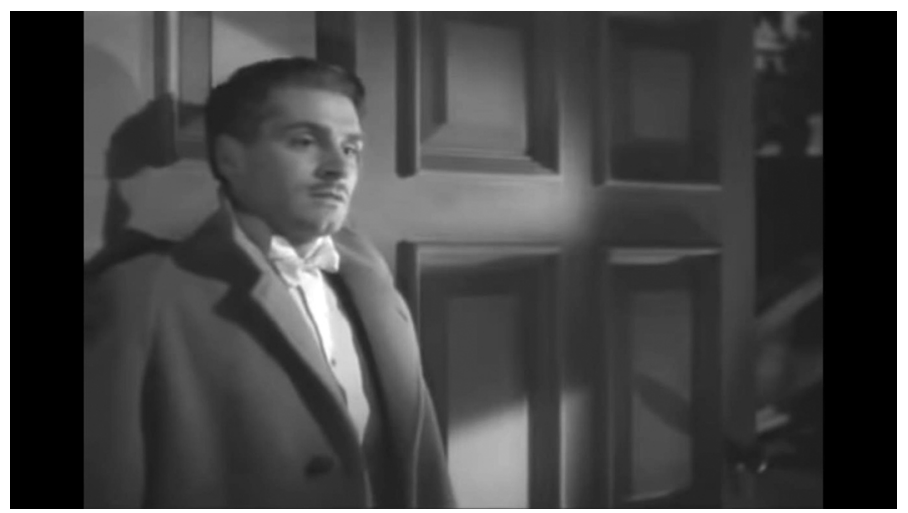

Figura 1. La confesión.

dónde salió. No hubo tal accidente. Rebeca no se ahogó. A Rebeca la maté yo de un tiro, estando en la casita de abajo. Llevé el cuerpo al camarote, salí al mar con el barquito y lo hundí allí, aquella noche, donde lo han encontrado hoy. La que está en el suelo del camarote es Rebeca. ¿Quieres mirarme ahora a los ojos y decirme que me quieres?

\section{Capitulo XX}

Maxim de Winter: -Entonces... ¿crees que yo estaba enamorado de Rebeca? ¿Crees que la maté porque la quería? ¡La odiaba, te digo que la odiaba! Nuestro matrimonio fue una farsa desde el primer momento. Rebeca era un ser vicioso, corrompido, despreciable por todos los conceptos, absolutamente por todos. Nunca nos quisimos, ni jamás gozamos juntos de un instante de felicidad. Era incapaz de querer a nadie, incapaz de sentir la más pequeña ternura o de tener un gesto de nobleza. ¡ $\mathrm{Ni}$ siquiera era normal!

\section{TEXTo FÍlmico}

Escena completa desde 1:24:00 hasta 1:35:18

Maxim de Winter: La mujer que sacaron del agua en Edgecombe y que está enterrada en nuestro panteón familiar no es Rebeca. Es el cuerpo de una mujer desconocida que nadie nos reclamó. Yo lo identifiqué, pero sabía que no era Rebeca. Todo fue un engaño. Yo sabía dónde estaba su cuerpo: en el suelo del camarote, en el fondo del mar.

Segunda Sra. de Winter: ¿Cómo lo sabías, Maxim?

Maxim de Winter: Porque yo lo puse allí. ¿Puedes mirarme ahora a los ojos y $[\ldots]$ decirme que me quieres? Lo ves, yo tenía razón. Es ya muy tarde. 
Maxim DE Winter: ¿Creías que amaba a Rebeca? ¿Lo creías? La odiaba. [...] Nunca fui feliz con ella. Era insensible al amor, a la ternura, a la decencia.

$[\ldots]$

Maxim de Winter: Creo que enloquecí de repente. Estaba ante mí, mirándome fijamente. Su desenfado me humillaba. Continuaba sonriendo. De pronto, se tambaleó y desplomó. Perdí la noción del tiempo. Cuando me acerqué, me di cuenta de que se habia golpeado la cabeza contra una de esas piezas. Me preguntaba por qué seguia sonriendo. Estaba muerta.

Segunda SRa. de Winter: Pero tú no lo hiciste. Fue un accidente.

MAXIm DE Winter: ¿Quién me creería? Estaba fuera de mí.

Al comparar las anteriores versiones, podemos ver que en la novela no cabe lugar a dudas de que Maxim es un asesino: «No hubo tal accidente. Rebeca no se ahogó. A Rebeca la maté yo de un tiro, estando en la casita de abajo». Sin embargo, como comentábamos en el epígrafe anterior, según el Código Hays un asesino no podía quedar impune. Si alguien cometía un asesinato, este debía recibir su castigo, por mucho que la mujer hubiera actuado con crueldad, engañado a su marido y aunque él no sintiera culpabilidad. Selznick y Hitchcock tuvieron que aceptar la propuesta de Breen de que todo quedara en un accidente. E. Sherwood ofreció una sugerencia que fue crucial en el rodaje de esta escena: la confesión de asesinato ocurriría, en lugar de en una sala de estar, en la casita junto al mar donde murió Rebeca. Allí Hitchcock se apoyaría en movimientos de cámara subjetiva en diferentes partes de la habitación que ayudarían al espectador a recrear la situación y completar el relato del Sr. De Winter (Boyd 121). Lo irónico de este cambio es que la obra de Daphne du Maurier es precisamente una novela de crimen y castigo, como veremos en el análisis de las escenas 2 y 3 .

\section{ESCENAS 2 Y 3: EL FINAL DEL CASO Y MANDERLEY EN LLAMAS}

Texto literario

Capitulo XXVIII

Escena del final del caso, tras la visita al médico en Londres

MaXim de Winter: -¿Crees que Julyan ha adivinado la verdad? -me preguntó. Me quedé mirándole por encima del borde de mi vaso, sin contestar.

MAXIM DE Winter: -Estoy seguro -dijo Maxim-que sabe lo que verdaderamente ocurrió.

Segunda Sra. de Winter: -Si lo sabe -dije yo-, no dirá nunca una palabra. MaXim de Winter: -No. No la dirá. [...]

MAXIm de Winter: -Creo que Rebeca me mintió con toda intención. Aquella mentira fue su última locura. Quería que la matase. Lo planeó todo en un momento. Supongo que por eso se reía y continuó riéndose hasta morir... [...] Si; fue su última broma. La mejor de todas. Ni siquiera ahora estoy seguro de que no me haya ganado la partida. 


\section{Capitulo XXVIII}

Escena de Manderley en llamas

Segunda SRa. De Winter: -¿Qué hora has dicho que era?

MAXIM De Winter: -Son las dos y veinte -me contestó.

Segunda SRA. De Winter:- - Qué raro! Parece enteramente como si estuviera empezando a amanecer por encima de las lomas.

MAXIM DE WinteR:-Por allí no puede ser. Estás mirando hacia el oeste.

Segunda Sra. de Winter: -Ya, ya. Pero es raro, ¿no?

No me contestó y seguí contemplando el cielo. La claridad parecía ir en aumento, semejante a los primeros albores del amanecer. Poco a poco aquella extraña luz se iba extendiendo por el cielo.

Segunda SRa. De Winter: -Oye -le dije-, la aurora boreal..., no se ve en verano, ¿verdad?

Maxim De Winter: -Eso no es la aurora boreal. Eso es Manderley.

Le miré, y vi su cara y la expresión de los ojos.

Segunda SRa. De Winter: -¿Qué es, Maxim? ¿Qué pasa?

Aceleró, apretando el pedal hasta el fondo. Coronamos la cuesta, y vimos Lanyon a nuestros pies. A nuestra izquierda brillaba la cinta plateada del río, ensanchándose más y más según se acercaba a la ría de Kerrith. La carretera de Manderley se perdía a lo lejos. No había luna. Encima de nuestras cabezas el cielo estaba negro como la tinta. Pero hacia el horizonte aparecía iluminado por una viva luz roja, como salpicado de sangre. El viento salobre del mar venía lleno de cenizas.

\section{TeXto FÍlmico}

Escena del final del caso, tras la visita al médico en Londres (escena completa desde 2:05:34 hasta 02:06:15)

Maxim De Winter: Frank.

Frank Crawley: Dime, Maxim.

MAXIM DE Winter: Hay algo que no sabes.

Frank Crawley: No, no lo hay.

MaXim DE Winter: Yo no la maté, pero ahora sé que al decirme lo del hijo pretendía que lo hiciese. Lo había previsto todo. Por eso mintió. Por eso quedó riéndose cuando...

Frank Crawley: No pienses ya más en ello.

MaXim de Winter: Gracias, Frank.

Escena de Manderley en llamas (escena completa desde 2:07:58 hasta 2:10:16)

MAXim DE Winter: Frank.

Frank Crawley: ¿Por qué has parado?

Maxim de Winter: Dime, ¿qué hora es? 


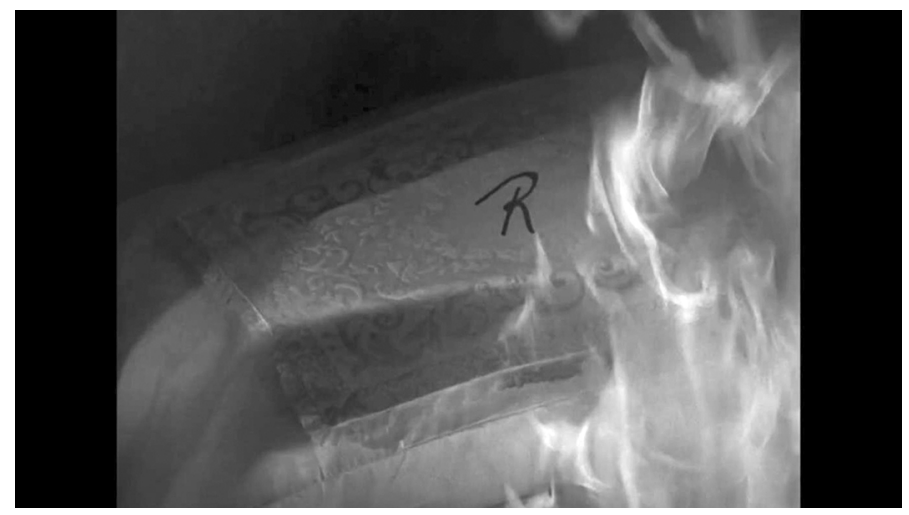

Figura 2. La R bordada en la almohada de Rebeca en llamas.

Frank Crawley: Se me ha parado el reloj, pero deben de ser las tres o las cuatro. MaXim de Winter: A esa hora no puede estar amaneciendo.

Frank Crawley: Es en invierno cuando se ve la aurora boreal, ¿no? Maxim de Winter: No es la aurora boreal. Es Manderley.

[...] [A la llegada a Manderley]

Segunda Sra. de Winter: Maxim. Gracias a Dios que has vuelto. MAXIM DE Winter: ¿Estás bien, cariño?

Segunda SRa. De Winter: Sí, estoy bien.

MAXim DE WinTer: Amor mío.

Segunda Sra. de Winter: Pero la Sra. Danvers se ha vuelto loca. Dijo que destruiría Manderley antes que vernos felices allí.

El asesino y su cómplice (la segunda Sra. De Winter) no quedan impunes ante el crimen en la novela, como podemos ver en las escenas 2 y 3 . En la escena 2, tras salir de la consulta del médico de Rebeca y haberse cerrado el caso como suicidio, la pareja es presa de su secreto. El fantasma de Rebeca les perseguirá y castigará de por vida, como ya avanza el Sr. De Winter cuando dice: «Aún no estoy seguro de que no me haya ganado la partida». En la escena 3, al final de la historia, ambos observan tristemente, desde la lejanía, un horizonte «salpicado de sangre»: el incendio desatado en Manderley. Tras ello, su castigo será vivir, como se apunta al principio de la novela, en el exilio, sin conseguir deshacerse ni por un instante de la sombra de Rebeca. Se trata, pues, de un final gótico funesto. En el final hitchcockniano alternativo, sin embargo, el castigo lo recibe Rebeca. Primero, Rebeca muere accidentalmente. Se trata de una muerte con fuerte carga moral, tras haber provocado a su marido fantaseando con qué pasaría si tuviera un hijo que terminara gobernando Manderley y nadie pudiera demostrar que no es suyo. La maldad de Rebeca vuelve a estar presente en la escena número 2, en la que el Sr. De Winter reafirma 
que él no mató a Rebeca y destaca cómo esta lo atormentó hasta el final. Posteriormente, en la escena 3, es decir, en el final de la película, se da muerte al fantasma de Rebeca. Esta última escena del filme representa, de hecho, un final feliz en el que el Sr. De Winter y su nueva esposa, al observar abrazados cómo arde Marderley con la Sra. Danvers dentro, vislumbran un futuro juntos lejos de los fantasmas del pasado. Esta idea es apoyada por un plano detalle final de la R de Rebeca ardiendo entre las llamas y con música ambiental con tono triunfal.

\section{ESCENA 4: LA HABITACIÓN DE REBECA}

\section{TeXto literario}

Capitulo XIV

SRA. DANVERs: -Esta era su cama. ¡Qué bonita! ¡Qué cama más bonita! ¿Verdad? La tengo siempre con esta colcha dorada, porque es la que ella prefería. Aquí, dentro de su bolsa, está el camisón. Lo ha estado mirando, ¿`no? Este fue el que se puso la última vez, la noche antes de morir. ¿Quiere tocarlo otra vez? -Sacó el camisón y me lo ofreció-. Tóquelo, cójalo, vea qué suave, qué ligero es, ¿verdad? No lo he lavado desde que ella se lo puso por última vez. Lo pongo así, y la bata y las chinelas, tal como lo preparé todo aquella noche que no volvió, la noche que se ahogó...

Dobló el camión y lo metió de nuevo en la bolsa. Volvió a cogerme del brazo y me llevó hacia la bata y las chinelas.

SRA. Danvers: -Yo lo hacía todo. Probamos doncellas y más doncellas, pero ninguna servía. "Dany -solía decirme-, no hay quien me sirva como tú. No quiero otra». Mire, su bata. Era mucho más alta que usted, como verá por lo larga que es. Póngasela, así, por fuera, para que vea..., ¿ ¿ve? ¡Le llega hasta los tobillos! ¡Qué tipo tenía! Estas son sus zapatillas. «Tírame las zapatillas, Danny», solía decirme. Para lo alta que era, tenía un pie muy chico. Mire, mire, meta la mano dentro. ¿Verdad, señora, que son muy estrechitas y pequeñas?

Me obligó a meter las manos en las chinelas, siempre sonriendo, mirándome a los ojos.

SRA. Danvers: -No hubiera pensado que era tan alta, ¿verdad? Estas zapatillas le vendrían muy bien a un pie chiquito. ¡Y tan delgada! Hasta que se ponía al lado de una, no se daba cuenta de lo alta que era. Era tan alta como yo. Pero, ¡ah!, metida en la cama, parecía una niña, con aquella mata de pelo moreno que rodeaba como un halo su cara...

$[\ldots]$

SRA. Danvers: -Aquí guardo las pieles. Todavía no se ha apolillado ninguna, ni creo que pase nunca. Ya pongo yo buen cuidado. Mire esta capa de martas cibelinas. Fue un regalo de Navidad que le hizo el señor. Una vez me dijo lo que había costado, pero ya no me acuerdo. Esta, de chinchilla, se la solía echar por los hombros cuando las noches refrescaban. Este ropero está lleno con sus trajes de noche. Lo ha abierto usted, ¿verdad? Veo que el pestillo no 


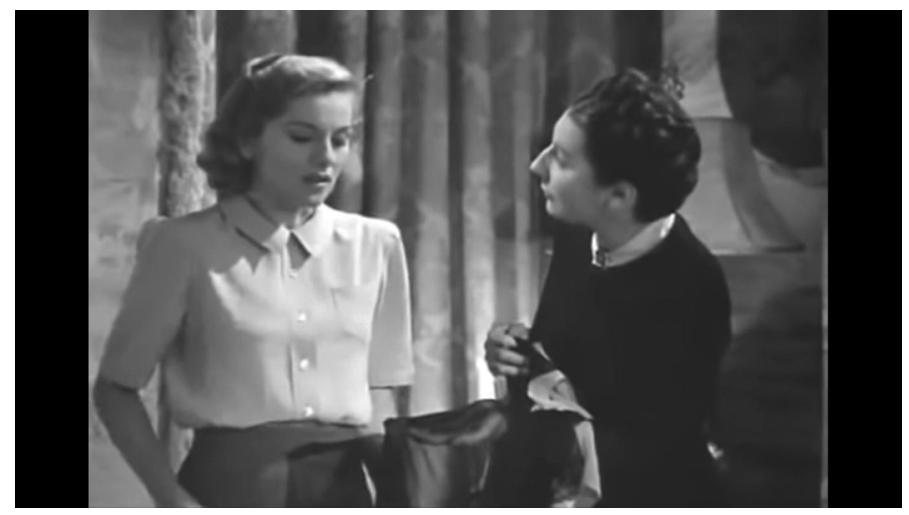

Figura 3. La habitación de Rebeca.

está corrido del todo. Creo que el señor prefería verla vestida de plata. Pero ella estaba bien con cualquier cosa, y todas las cosas le iban bien. Con este de terciopelo estaba divina. ¡Acérqueselo a la cara! ¿Qué suave! ¿Verdad? ¿No lo nota? El perfume aún se conserva. Casi se imaginaría una que se lo acaba de quitar. Yo siempre sabía, cuando entraba en su cuarto, si ella había estado allí antes. Siempre quedaba algo de su perfume detrás. En este cajón está su ropa interior. Este juego rosa no llegó a estrenarlo.

\section{TeXto fílmico}

Escena completa desde 01:04:00 hasta 01:10:00

SRA. DANVERs: Siempre ha deseado ver esta habitación, ¿verdad, señora? ¿Por qué no me pidió que se la enseñara? Estaba dispuesta a hacerlo. Es bonita, ¿ iverdad? La más bonita que usted haya visto. Todo se conserva como a ella le gustaba. Nada se ha alterado desde aquella última noche. Venga, le enseñaré el vestidor. Aquí guardo sus vestidos. Le gustaría verlos, ¿no? Mire qué suave. Es un regalo de Navidad del señor. Siempre le hacía costosos regalos. Todo el año. Guardo su ropa interior aqui. La hicieron para ella las monjas del Convento de Santa Clara. Yo la esperaba siempre, por tarde que fuese. A veces ella y el señor llegaban de madrugada. Al desvestirse me hablaba de la fiesta a la que había asistido. Conocía a personas importantes y todo el mundo la quería. Al terminar el baño, iba al dormitorio y se dirigía al tocador [...] Yo misma bordé para ella esta bolsa y está siempre aquí. ¿Ha visto algo más delicado? Mire cómo se ve mi mano.

Como vemos en la novela, aunque reflejadas de manera sutil, encontramos varias frases (marcadas en cursiva) que dejan entrever una atracción sexual o una relación lésbica entre la Sra. Danvers y Rebeca. El guion cinematográfico quiso 
mantener la misma esencia de la escena, pero, como veíamos en el epígrafe anterior, la oficina del Código de Producción de Hollywood rechazó esta propuesta en la que se entreveían interferencias de perversión sexual (la atracción sexual de la Sra. Danvers por Rebeca) para la moral católica. Hitchcock empleó otras técnicas para expresar de manera sutil lo que no podía expresar de modo manifiesto. En la película se redujeron al mínimo los diálogos en los que se intuía una relación íntima entre Rebeca y la Sra. Danvers. Sin embargo, la escena estaba cargada de planos muy íntimos, de erotismo y tensión. En uno de ellos, por ejemplo, se muestra a la Sra. Danvers, quieta junto a la segunda Sra. De Winter, acariciando la lencería de Rebeca. Asimismo, en la versión fílmica aparecen dos frases que no pertenecen al texto literario original. Por una parte, la referencia a que fueron unas monjas del Convento de Santa Clara las que elaboraron la ropa interior de Rebecca y, por otra, la frase en la que la Sra. Danvers toma el camisón transparente de Rebeca en sus manos y añade: «Mire cómo se ve mi mano». Dos frases estas que sobre papel podían parecer inocentes, pero que combinadas con la imagen dejaban volar la imaginación de los espectadores.

\section{CONCLUSIONES}

El estudio comparativo de la censura de Rebeca frente a dos códigos de censura coetáneos que afectaron, por un lado, a toda producción artística, literaria y audiovisual en Espańa (Ley de Prensa de 1938) y, por otro, a la estética y el mensaje de las producciones cinematográficas en Estados Unidos desde 1930 hasta 1968 (Código de Producción de Hollywood) nos permite extraer las siguientes conclusiones. En primer lugar, que si bien los Códigos eran similares en cuanto a época, bases -ambos eran apoyados por la Iglesia católica-, y a su ideario -representaban un fuerte control moral-, no lo eran tanto en la práctica. La obra y adaptación cinematográfica que aquí hemos analizado es una prueba de ello. Mientras que el Código Hays no permitió que el asesinato de Rebeca hubiera sido obra de su marido - quien además salía impune- y lo transformó en un accidente casual, esto no pareció ser problema alguno para la censura franquista. Para los lectores encargados de la censura este acto de violencia machista estaría ampliamente justificado: Rebeca era adúltera (pecado), nulípara (error), fuerte (inadecuado) y superior al Sr. Danvers (inaceptable). Así, su beneplácito reiterado a las peticiones de publicación de obra, traducción, adaptación cinematográfica (con el doblaje) es una carta blanca a la violencia machista. Y mientras la censura franquista pasó por alto o no advirtió las implicaciones textuales a la homosexualidad de la Sra. Danvers, el puritano Código Hays se encargó de matizarlas, modificando así el mensaje de la autora y contribuyendo a la edificación de un marco que desde Hollywood divulgara un pensamiento puritano, maniqueísta, austero, racista, misógino y homófobo. 


\section{REFERENCIAS BIBLIOGRÁFICAS}

Abellán, Manuel L. Censura y creación literaria en España (1939-1976). Barcelona: Península, 1980.

BARR, Charles. «Hitchcock and adaptation», en Bravo, J.M (coord.), La literatura en lengua inglesa y el cine, Valladolid: Instituto de Ciencias de la Educación de la Universidad de Valladolid, 1993, pp. 115-125.

Bell, Matthew. «Fan tracks down lost stories of Daphne Du Maurier». The Independent, 20 febrero 2011. <https://www.independent.co.uk/arts-entertainment/books/news/fan-tracks-downlost-stories-of-daphne-du-maurier-2220130.html>.

Berenstein, Rhona J. «Adaptation, Censorship, and Audiences of a Questionable Type: Lesbian Sightings in Rebecca (1940) and The Uninvited (1944)». Cinema Journal 3:3, (1998), pp. $16-37$.

Boyd, D. «The trouble with Rebecca», en Barton Palmer, R y Boyd, Davi (eds.), Hitchcock at the source. The Auteur as Adaptor, Nueva York: State University of New York Press, 2011, pp. 117-127.

Bou, N. «La puesta en discurso de la sexualidad en el cine clásico de Hollywood». L'Atalante 28, pp. 19-31.

Camp, J. «John Buchan and Alfred Hitchcock». Literature Film Quarterly, 6. (1978), pp. 230-240.

Cisquella, G., Erviti, J.L. y Sorolla, J.A. La represión cultural en el franquismo. Diez años de censura de libros durante la Ley de Prensa (1966-1976). Barcelona: Anagrama, 1977.

Coe, J. "Good book, great film». The Guardian, 1 abril 2011. <https://www.theguardian.com/ books/2011/apr/01/book-adaptations-film-jonathan-coes.

Del Toro, C. «Rebeca y El Ministerio del miedo: Dos dimensiones diferentes de la adaptación fílmica", en Santamaría, J.L et al. (eds.), Trasvases culturales: literatura, cine, traducción, Vitoria: Universidad del País Vasco, 1997, pp. 97-106.

Du Maurier, Daphne. Rebeca. Traducción de Gloria Martínez. Barcelona: Ediciones B, 1993.

Du Maurier, Daphne. Rebecca. London: Hachette Digital, 2003.

Fowler, C. «Invisible Ink No 66- Frank Baker». The Independent, 27 febrero 2011. <https:// www.independent.co.uk/arts-entertainment/books/features/invisible-ink-no-66-frankbaker-2226592.html>.

Forster, Margaret. Daphne du Maurier. Londres: Arrow, 1994.

Hernández Miñano, P y Martín Núñez, V. «Guardar las formas. Autorregulación y estética el clasicismo cinematográfico». L'Atalante, 28, pp. 7-16.

Нıтснсоск, А. (productor y director). The Birds. United States: Alfred J. Hitchcock Productions, 1963.

Martos, M. «La censura (1938-1978). Otro elemento de la vida teatral». Bibud,18:2, (2002), pp. 257-274.

Montiel, T. «Los inicios de la censura en el cine». ArthyHum, 16, 2015, pp. 54-69.

Muñoz Cáliz, B. «Notas sobre la crítica teatral durante el franquismo: las difusas fronteras entre crítica y censura». Las puertas del drama: revista de la Asociación de Autores de Teatro, 15 (2003), pp. 19-25. 
Neuschäfer, H. Adiós a la España eterna. La dialéctica de la censura. Novela, teatro y cine bajo el franquismo. Barcelona: Anthropos, 1994.

Pommer, E., Laughton, C. (productores) y Нiтchсоск, A. (director). Jamaica Inn. UK: Mayflower Productions, 1939.

Rambal, E., Soriano Torres, M. y Pérez Bultó, J.J. Comedia dramática de gran espectáculo, en un prólogo y dos jornadas, divididas en veintisiete cuadros, adaptación de la novela del mismo título de Daphne du Maurier. Madrid: Librerías de ferrocarriles, 1944.

Rodríguez, A.M. «El Código de Producción de Hollywood (1930-1966): censura, marcos (frames) y hegemonía». Zer, 20:39 (2015), pp. 177-193.

Selznick, D.O. (productor) y Нiтснсоск, A. (director). Rebecca. United States: Selznick International Pictures, 1940.

Zaragoza, Gora. et al. "Daphne du Maurier en español: traducción, adaptación y censura», en Zaragoza, Gora et al. (eds.), Traducción, género y censura en la literatura y en los medios de comunicación, Granada: Comares, 2018.

\section{Filmografía}

Rebecca (1940). Película dirigida por Alfred Hitchcock. Estados Unidos, Selznick International. Versión en castellano en Filmin: https://www.filmin.es/pelicula/rebeca. 
